\title{
Psychogenic Nonepileptic Seizures: What a Neurologist Should Know
}

\author{
Taoufik Alsaadi ${ }^{1,2 *}$, Tarek M. Shahrour ${ }^{2,3}$ \\ ${ }^{1}$ Department of Neurology, Sheikh Khalifa Medical City, Abu Dhabi, UAE \\ ${ }^{2}$ The Emirati League against Epilepsy (ELAE), Abu Dhabi, UAE \\ ${ }^{3}$ Department of Psychiatry, Sheikh Khalifa Medical City, Abu Dhabi, UAE \\ Email: talsadi@skmc.ae
}

Received 24 June 2014; revised 11 August 2014; accepted 25 August 2014

Copyright (C) 2014 by authors and Scientific Research Publishing Inc.

This work is licensed under the Creative Commons Attribution International License (CC BY). http://creativecommons.org/licenses/by/4.0/

(c) (i) Open Access

\section{Abstract}

Psychogenic nonepileptic seizures (PNES) are episodes of movement, sensation or behavior changes similar to epileptic seizures but without neurological origin. They are somatic manifestations of psychological distress. The aim of this article is to provide a comprehensive review of the practical aspects of this, most often misdiagnosed disorder, which will be of clinical relevance to all practicing neurologists. Patients with PNES are often misdiagnosed and treated for epilepsy for years, resulting in significant morbidity. Video-EEG monitoring is the gold standard for diagnosis. Five to ten percent of outpatient epilepsy populations and 20 to 40 percent of inpatient and specialty epilepsy center patients have PNES. These patients inevitably have comorbid psychiatric illnesses, most commonly depression, post-traumatic stress disorder (PTSD), other dissociative and somatoform disorders, and personality pathology, especially borderline type. Many have a history of sexual and physical abuse. 75 to 85 percent of patients with PNES are women. Although PNES can occur at any age, they typically begin in young adulthood. Treatment involves discontinuing antiepileptic drugs in patients without concurrent epilepsy and referring for appropriate psychiatric care. Additional larger controlled studies to determine the best treatment modalities are needed.

\section{Keywords}

Psychogenic Nonepileptic Seizures, Epileptic Seizures, Diagnosis

\section{Introduction}

Nonepileptic seizures (NES) are involuntary episodes of movement, sensation or behavior similar to epileptic *Corresponding author. 
seizures that do not result from abnormal cortical discharges. They can mimic any kind of epileptic seizure, being mistaken for generalized tonic-clonic, absence, simple and complex partial seizures [1]. Neurologist needs to be aware of this problem because early recognition and appropriate treatment can prevent significant iatrogenic harm, and would result in a better outcome.

NES have been recognized since ancient times as a form of hysteria; Jean Charcot first described nonepileptic seizures as a clinical disorder in the late $1800 \mathrm{~s}$, calling it "hysteroepilepsy" or "epileptiform hysteria" [2]. The term nonepileptic seizure is preferable to the older terms hysterical seizure and pseudoseizure because those terms are considered pejorative [3].

NES are classified as physiologic or psychogenic in origin (Table 1). Physiologic NES, which are less common than psychogenic NES, have multiple etiologies. They may be syncopal episodes, complicated migraines, panic attacks, transient ischemic attacks, autonomic dysfunction, cardiac arrhythmias, hypoglycemia, drug intoxication or withdrawal or alcohol intoxication or withdrawal. Movement disorders, sleep disorders, and vestibular symptoms may also be mistaken for NES [4].

More commonly, non-epileptic seizures are psychogenic in origin. They are thought to be a form of physical manifestation of psychological distress. Psychogenic non-epileptic seizures (PNES) are grouped in the category of psycho-neurologic illnesses like other conversion and somatization disorders, in which symptoms are psychological in origin but neurologic in expression [5]. The remainder of this review article will concentrate on psychogenic nonepileptic seizures.

\section{Diagnosis}

The search for an easier and more cost-effective tools of differentiating epileptic seizures (ES) from PNES continues to be a real challenge. Several factors have been considered when diagnosing PNES seizures, but the gold standard for diagnosis remains the inpatient video-electroencephalography (vEEG) monitoring. Several indicators have been used historically to make this distinction; example of these indicators are the presence or absence of self-injury and incontinence, ability to induce seizures by suggestion, psychological tests, historical factors and ambulatory EEG monitoring [1] [6].

One of the widely studied tools is the post-ictal prolactin (PRL) level measurement. Although Studies are conflicting on the reliability of this tool, one recent extensive review of the literature has outlined the value of this test. It emphasizes that elevated PRL levels 10 - 20 minutes post-ictaly are highly predictive of either generalized tonic-clonic or complex partial seizures. Pooled sensitivity, however, was higher for generalized tonicclonic seizures (60.0\%) than for complex partial seizures (46.1\%), while the pooled specificity was similar, for both (approximately 96\%). Furthermore, the data were insufficient, however, to establish this validity for simple partial seizures. Two cited studies in this review were consistent in showing PRL elevation after tilt-test-induced syncope. Similarly, inconclusive data exists regarding the value of serum PRL following status epilepticus, repetitive seizures, and neonatal seizures. These observations conclude that elevated serum PRL assay, when measured in the appropriate clinical setting at 10 to 20 minutes after a suspected event, is a useful adjunct

Table 1. Classification of nonepileptic seizures.

\begin{tabular}{|c|c|}
\hline \multicolumn{2}{|c|}{ Nonepileptic Seizures } \\
\hline Physiologic & Psychogenic \\
\hline $\begin{array}{l}\frac{\text { Cardiac arrhythmias }}{\text { Complicated migraines }} \\
\frac{\text { Drug/Toxic effects }}{\text { Dysautonomia }} \\
\underline{\text { Hypoglycemia }} \\
\frac{\text { Movement disorders }}{\text { Panic attacks }} \\
\underline{\text { Sleep disorders }} \\
\text { Syncopal episodes } \\
\text { Transient ischemic attacks (TIAs) } \\
\text { Vestibular symptoms }\end{array}$ & $\begin{array}{l}\frac{\text { Misinterpretation of physical symptoms }}{\text { Psychopathological processes: }} \\
\frac{\text { Conversion disorder }}{\underline{\text { Somatization disorders }}} \\
\frac{\text { Dissociative disorders }}{\text { Anxiety disorders (including PTSD) }} \\
\underline{\text { Hypochondriasis }} \\
\underline{\text { Psychoses }} \\
\underline{\text { Reinforced behavior patterns in cognitively impaired patients }} \\
\text { Response to acute stress without evidence of psychopathology }\end{array}$ \\
\hline
\end{tabular}


for the differentiation of generalized tonic-clonic or complex partial seizure from PNES among adults and older children. On the other hand, serum PRL assay does not distinguish ES from syncope. Moreover, the use of serum PRL assay has not been established in the evaluation of status epilepticus, repetitive seizures, and neonatal seizures [7].

Various self-administered questionnaires were developed to make the diagnosis of PNES easier. One particular questionnaire was found useful as a screening tool and can be used to hasten the referral of these patients for (vEEG) [8]. Likewise, semiotics also can be used as a screening tool. Studies have shown that semiological differences between PNES and ES are reliable when performed by experts but, unfortunately, they are not as reliable, when obtained from relatives and lay persons [9].

Another suggested tool is the measurement of Heart Rate Variability in all suspected patients. A preliminary study has shown an increase of HRV in the ES patients as compared to patients with PNES [10].

To this date, the definitive diagnosis is only achieved with vEEG monitoring, in which, the patient is observed having his/her typical seizures, with the lack of any accompanying abnormality on the ictal EEG recording. Family members or witnesses who are familiar with the patient's habitual events must agree that the recorded episodes are their typical events and they are the only ones that they observe the patient is suffering from. The importance of using vEEG for diagnosis was underscored in a study [11] evaluating the diagnoses of patients referred to the inpatient vEEG-monitoring unit for characterization of their seizures. Twenty-four percent had been misdiagnosed: 22 patients previously diagnosed with epilepsy were found to have NES, and four patients previously diagnosed with NES were found to have epileptic seizures. Epileptologists or neurologists with experience in epilepsy referred all study patients. Interestingly, even epilepsy specialists misdiagnosed seizure types in nearly a quarter of cases. Despite the fact that the vEEG is the gold standard test, the inter-rater reliability of this tool was found in one study to be moderate in value when the test was used without any supporting historical and semiological data on the patients in question [12]. One way of increasing the diagnostic yield and reducing the waiting time of the vEEG is to use the administration of single placebo induction, which has showed a very promising result in a preselected population in one study [13]. Similarly, another study showed that induction can be achieved without placebo [14]. This approach, however, remains a controversial one and creates so much debate from an ethical point of view, which is not the scope of this review article.

On that note, historical details and clinical features that are suggestive (but not diagnostic) of nonepileptic seizures are reviewed in Table 2 \& Table 3. Typical PNES features include a gradual onset, long duration, waxing and waning course, and disorganized, asymmetrical motor activity [15]. PNES also lack the stereotypy of epileptic seizures; that is, the pattern of symptoms and sequence of events vary between seizures. Not all seizures with these features are PNES, however. Frontal lobe seizures are often mistaken for nonepileptic seizures because of their dramatic motor and vocal outbursts, possible retained consciousness and short post-ictal period. They may be distinguished from PNES by their brief duration, stereotypical nature, and tendency to begin during sleep [15].

Early diagnosis of psychogenic non-epileptic seizures is a critical step to reduce morbidly and mortality. Unfortunately, accurate diagnosis is often delayed; there is a mean latency of 7.2 years between manifestation and diagnosis of PNES [16]. PNES patients experience significant iatrogenic morbidity from inappropriate treatment of epileptic seizures, including adverse effects of antiepileptic drugs (AEDs) and emergency visits for pseudo-

Table 2. Historical and clinical details suggesting a diagnosis of psychogenic nonepileptic seizures.

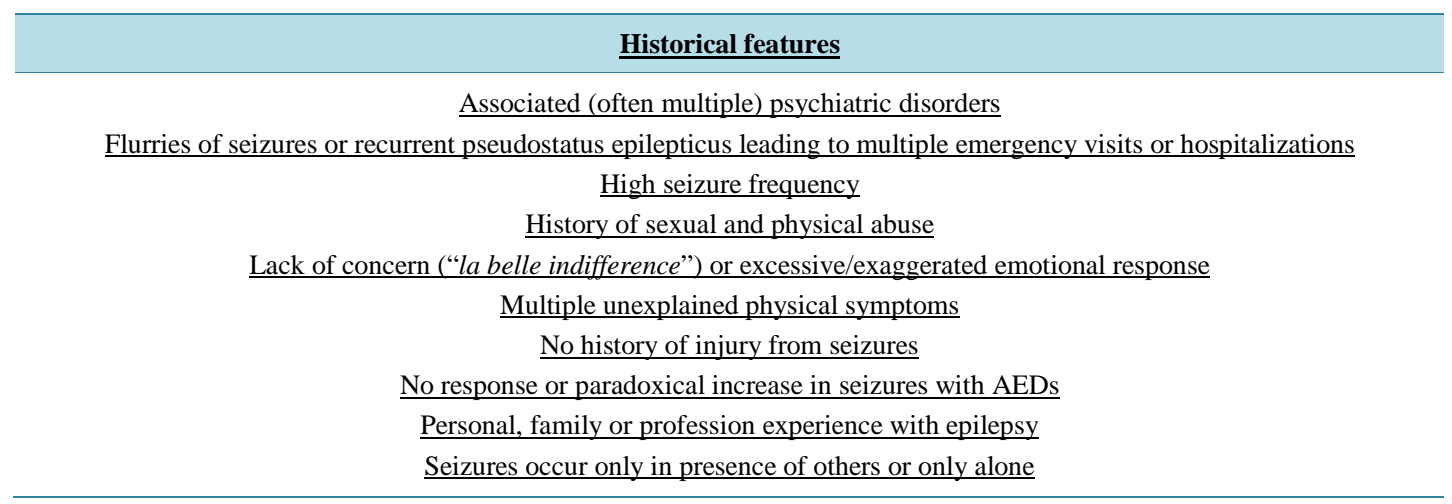


Table 3. Clinical signs suggesting a diagnosis of psychogenic nonepileptic seizures.

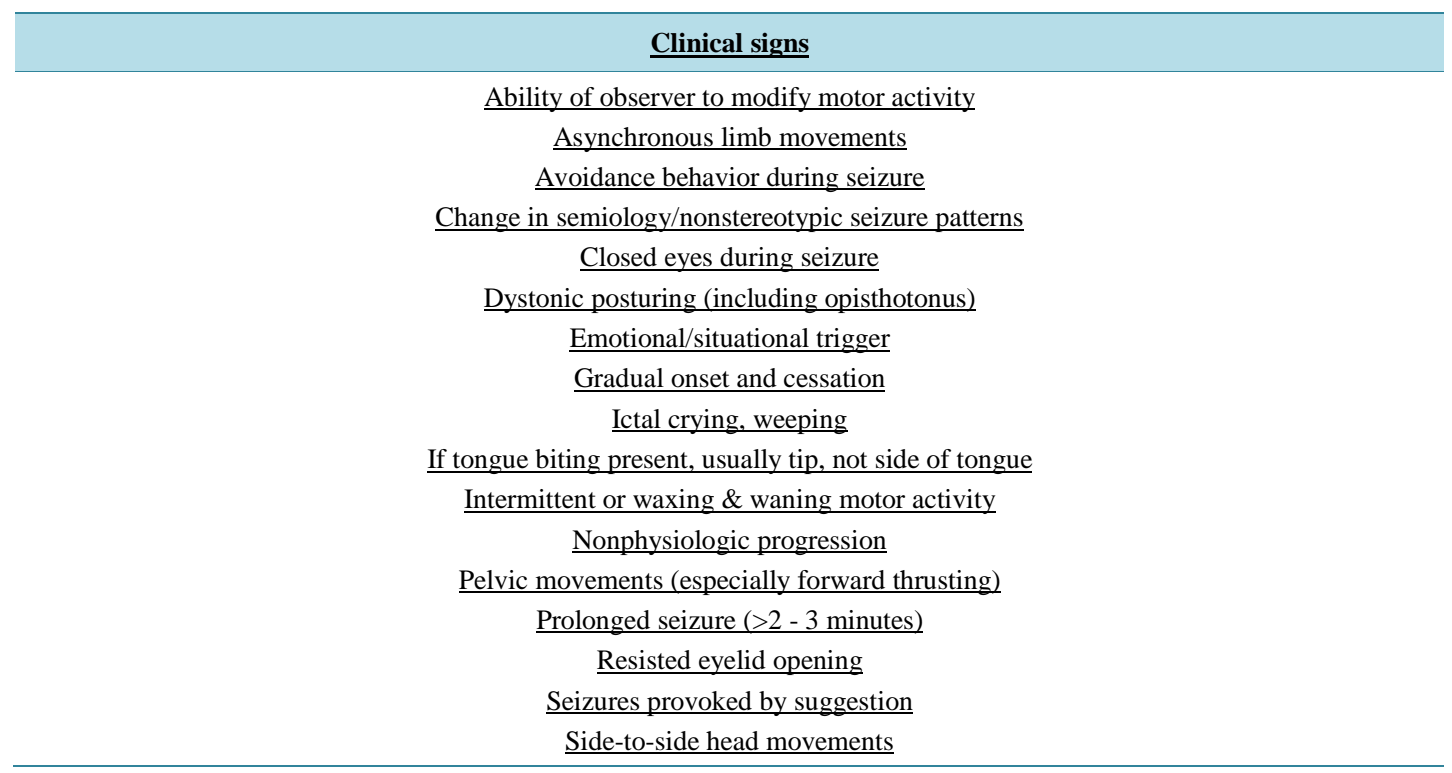

Adapted from Rowan [1], Barry [15] and Reuber \& Elger [16].

status, with associated aggressive and potentially harmful interventions including intubation. On the other hand, definitive diagnosis may be therapeutic as well; some patients will stop having PNES after being informed unambiguously of their diagnosis [17]. Finally, and from a healthcare costs point of view, it is important to diagnose PNES early in its course. One study [18] demonstrated an 84 percent reduction in total seizure-related medical charges in the six months after diagnosis: average diagnostic test charges decreased by 76 percent and medication charges by 69 percent, while outpatient visits decreased 80 percent and emergency department visits by 97 percent. Neurologits have an important role to play in the timely diagnosis of PNES through early referral of patients with apparently intractable seizures to an epilepsy program. About 60 percent of patients with newly diagnosed epilepsy will be controlled on a moderate dose of a single antiepileptic drug, usually the first or a second drug chosen; only about 10 percent with inadequate control of seizures on the first AED will become seizure-free [19] [20]. Thus, the threshold for diagnosing a patient with intractable seizures should be low and a referral to an epilepsy center for clarification of the diagnosis should be prompt.

PNES has serious negative effects on patients' lives. Health-related quality of life is significantly lower in patients with PNES than patients with epilepsy, even when compared with patients with intractable epilepsy [21]. This decreased quality of life is associated with the presence of psychopathology and with adverse effects of antiepileptic drugs [21], further emphasizing the importance of early diagnosis, cessation of AEDs, and treatment of the underlying psychiatric illness.

\section{Epidemiology}

Two to 33 per 100,000 people in the general population have nonepileptic seizures, making them about as common as multiple sclerosis and trigeminal neuralgia [22]. Five to 10 percent of outpatient epilepsy populations have non-epileptic seizures, compared to 20 to 40 percent in inpatient and specialty epilepsy centers [3] [23]. Seventy-five to 85 percent of PNES patients are female [24]. PNES tend to begin in young adulthood similar to conversion disorder, but are seen in a wide range of ages [24]. The prevalence of PNES is increased in patients with head injuries, learning disabilities and isolated neuropsychological deficits [16], and PNES patients have higher than average rates of abnormal MRIs and EEGs, suggesting that physical brain disease may play a role in the development of PNES [25]. PNES are also seen in patients with CNS lesions that are associated with an increased risk of developing epilepsy, such as stroke, trauma, infection and malformation [26], as well as in patients with hippocampal sclerosis [27], an often-identified cause of temporal lobe epilepsy. The presence of abnormalities on MRI or EEG may therefore delay diagnosis and treatment of PNES.

Estimates of the co-existence of epilepsy and PNES have varied widely, from 5 percent to more than 60 percent 
depending on the study setting and diagnostic criteria used [3]. Recent studies using strict criteria for a diagnosis of epilepsy find that only 5 to 10 percent of patients with NES have concurrent epileptic seizures [23] [28].

\section{Etiology}

All psychogenic nonepileptic seizures function as a coping mechanism [29]. PNES patients consistently perceive their lives as stressful, and are more likely to use maladaptive coping strategies to handle stress [30]. In PNES, psychological conflicts are translated into a physical symptom, the seizure. In this way, intolerable distress is dissociated from the painful conscious experience of the trauma or forbidden emotions causing the distress [31] [32]. Thus genuine PNES (as opposed to factitious disorder or malingering) are necessarily not intentional; they are created as a psychological defense mechanism to keep the internal stressors out of conscious awareness [31].

PNES do not have a single cause; rather, they are the product of several different causal pathways (Table 1). PNES may be the result of psychopathological processes; they may be a response to acute stress in a patient without evidence of psychopathology, or a reinforced behavior pattern in cognitively impaired individuals. Rarely, malingering or factitious disorder present as PNES [33]. Forty-three to 100 percent (median 73.5 percent) of PNES patients have a current psychiatric disorder [34] (Table 4). These tend to be trauma-related disorders, including post-traumatic stress (PTSD) and other anxiety disorders; depressive disorders, and conversion, somatization and dissociation disorders. Personality pathology, particularly of the borderline type, are common [35]. Frequently these patients have other dissociative and somatization symptoms in addition to PNES [24] [36].

There is often a history of, or current physical or sexual abuse [30] or significant psychosocial stressors for which the patient perceives no resolution [37] [38]—what Griffith [37] called "unspeakable dilemmas". These dilemmas frequently involve dysfunctional family interaction and communication [24] [30]. An often-cited prospective study [31] showed that 84 percent of the PNES patients had experienced trauma. More recently, Dikel et al. [39] found significantly higher rates of PTSD, childhood sexual abuse, dissociative symptoms and history of assaultive trauma in patients with PNES compared to epileptic controls. Physical and sexual abuse have been linked to increased rates of several somatization syndromes, including PNES [32].

To figure out why a particular patient is having PNES, the clinician must understand what the psychological function of the seizure is [40]. A detailed and systematic psychiatric evaluation and an assessment of family, social, financial and employment problems should provide an insight to this [41].

\section{Disease Course \& Prognosis}

Non-epileptic seizures are not a single entity or disorder, so the course is variable and depends on the underlying etiology. However, outcome studies allow some generalizations about PNES patients as a group. Seizure cessation occurs in about 40 percent, seizure reduction occurs in a third of patients, and another third has chronic, unimproved PNES [42]. In a study assessing the 1 to 10 year outcomes of 164 patients with PNES [17], 44 percent had a poor outcome, (defined as not seizure-free and dependent-i.e. retired because of ill health or unemployed),

Table 4. Comorbid psychiatric disorders in patients with nonepileptic seizures.

\begin{tabular}{ccc}
\hline Diagnosis & Current & Lifetime \\
\hline Any dissociative disorder & $91 \%$ & $93 \%$ \\
Any somatoform disorder & $89 \%$ & $98 \%$ \\
Any affective disorder & $64 \%$ & $98 \%$ \\
Personality disorder & $62 \%$ & $62 \%$ \\
PTSD & $49 \%$ & $58 \%$ \\
Major Depressive Disorder & $47 \%$ & $80 \%$ \\
Anxiety d/o other than PTSD & $47 \%$ & $51 \%$ \\
Conversion symptoms-not seizures & $4 \%$ & $82 \%$ \\
\hline
\end{tabular}

Arranged by frequency (current); adapted from Bowman \& Markand [31]. 
40 percent had an intermediate outcome, (seizure-free but dependent, or not seizure-free but living independently), and only 16 percent had a good outcome, (seizure-free and living independently). At more than 11 years after onset and 4 years after diagnosis, 71 percent were still having PNES, and 56 percent were still dependent. This is worse than the outcome for newly diagnosed epilepsy, and equivalent to the outcome for other somatoform disorders [17]. People having both epileptic and non-epileptic seizures may have less favorable outcomes, but there are still no long-term studies specifically evaluating that population.

\section{Treatment}

As mentioned in this article there is a proven therapeutic value for the mere communication of the diagnosis. From a pharmacological point of view, a single pilot randomized controlled trial (RCT) study on the use of SSRIs in the treatment of PNES have shown good positive preliminary results. Cleary, this finding needs to be replicated in a large double blinded study to confirm this finding [43]. On the other hand psychological treatments remain the preferred choice for clinicians involved with PNES as shown in a recent survey [44]. Unfortunately, there is still no RCT on psychological treatment of PNES [33] [34]. Treatment recommendations are based on the logical but unproven theory that because the non-epileptic seizures are psychogenic in origin, they will respond to psychiatric treatment. Two uncontrolled studies [24] [45] showed that psychotherapy was more effective than no intervention. Various psychotherapeutic techniques with proven efficacy for other disorders have been applied to PNES patients with similar psychiatric profiles. There are several proposed current treatment recommendations based on the underlying etiologies of PNES [46]. All recommendations, however, are based on anecdotal evidence or small, uncontrolled studies.

LaFrance and Devinsky [33] offer a model of neuropsychiatric treatment formulation for PNES. The first step is proper diagnosis with a thorough history and exam and inpatient video-EEG monitoring. Second, the diagnosis should be presented to the patient and family. Third, psychiatric treatment is determined by creating a problem list identifying predisposing factors, precipitants to seizures, and perpetuating factors; this list then informs the prescription of the appropriate psychotherapies. Finally, addressing pharmacotherapy involves tapering antiepileptic drugs (in patients with exclusively nonepileptic seizures), which was shown to be safe when done under proper clinical surveillance [47] as well as with the titration of appropriate psychotropics for the management of psychiatric comorbidities.

\section{References}

[1] Rowan, A.J. (2000) Diagnosis of Non-Epileptic Seizures. In: Gates, J.R. and Rowan, A.J., Eds., Non-Epileptic Seizures, 2nd Edition, Butterworth-Heinemann, Boston, 15-30.

[2] Krumholz, A. (1999) Nonepileptic Seizures: Diagnosis and Management. Neurology, 53, S76-S83.

[3] Gates, J.R. (2000) Epidemiology and Classification of Non-Epileptic Events. In: Gates, J.R. and Rowan, A.J., Eds., Non-Epileptic Seizures, 2nd Edition, Butterworth-Heinemann, Boston, 3-14.

[4] Andermann, F. (2000) Non-Epileptic Paroxysmal Neurological Events. In: Gates, J.R. and Rowan, A.J., Eds., Non-Epileptic Seizures, 2nd Edition, Butterworth-Heinemann, Boston, 51-69.

[5] Bourgeois, J.A., Chang, C.H., Hilty, D.M. and Servis, M.E. (2002) Clinical Manifestations and Management of Conversion Disorders. Current Treatment Options in Neurology, 4, 487-497. http://dx.doi.org/10.1007/s11940-002-0016-2

[6] Iriarte, J., Parra, J., Urrestarazu, E. and Kuyk, J. (2003) Controversies in the Diagnosis and Management of Psychogenic Seizures. Epilepsy \& Behavior, 4, 354-359. http://dx.doi.org/10.1016/S1525-5050(03)00113-6

[7] Chen, D.K., So, Y.T. and Fisher, R.S. (2005) Use of Serum Prolactin in Diagnosing Epileptic Seizures: Report of the Therapeutics and Technology Assessment Subcommittee of the American Academy of Neurology. Neurology, 65, 668675. http://dx.doi.org/10.1212/01.wnl.0000178391.96957.d0

[8] Syed, T.U., Arozullah, A.M., Loparo, K.L., Jamasebi, R., Suciu, G.P., Griffin, C., Mani, R., Syed, I., Loddenkemper, T. and Alexopoulos, A.V. (2009) A Self-Administered Screening Instrument for Psychogenic Nonepileptic Seizures. Neurology, 72, 1646-1652. http://dx.doi.org/10.1212/WNL.0b013e3181a55ef7

[9] Syed, T.U., LaFrance Jr., W.C., Kahriman, E.S., Hasan, S.N., Rajasekaran, V., Gulati, D., Borad, S., Shahid, A., Fernandez-Baca, G., Garcia, N., Pawlowski, M., Loddenkemper, T., Amina, S. and Koubeissi, M.Z. (2011) Can Semiology Predict Psychogenic Nonepileptic Seizures? A Prospective Study. Annals of Neurology, 69, 997-1004. http://dx.doi.org/10.1002/ana.22345

[10] Ponnusamy, A., Marques, J.L.P. and Reuber, M. (2012) Comparison of Heart Rate Variability Parameters during 
Complex partial Seizures and Psychogenic Non-Epileptic Seizures. Epilepsia, 53, 1314-1321. http://dx.doi.org/10.1111/j.1528-1167.2012.03518.x

[11] Alsaadi, T.M., Thieman, C., Shatzel, A. and Farias, S. (2004) Video-EEG Telemetry Can Be a Crucial Tool for Neurologists Experienced in Epilepsy When Diagnosing Seizure Disorders. Seizure, 13, 32-34. http://dx.doi.org/10.1016/S1059-1311(03)00072-4

[12] Benbadis, S.R., LaFrance Jr., W.C., Papandonatos, G.D., Korabathina, K., Lin, K., Kraemer, H.C. and For the NES Treatment Workshop (2009) Interrater Reliability of EEG Video Monitoring. Neurology, 73, 843-846. http://dx.doi.org/10.1212/WNL.0b013e3181b78425

[13] Chen, D.K., Izadyar, S., Collins, R.L., Benge, J.F., LeMaire, A.W. and Hrachovy, R.A. (2011) Induction of Psychogenic Non-Epileptic Events: Success Rate Influenced by Prior Induction Exposure, Ictal Semiology, and Psychological Profiles. Epilepsia, 52, 1063-1070. http://dx.doi.org/10.1111/j.1528-1167.2011.02985.X

[14] Benbadis, S.R., Johnson, K., Anthony, K., Caines, G., Hess, G., Jackson, C., Vale, F.L. and Tatum IV, W.O. (2000) Induction of Psychogenic Nonepileptic Seizures without Placebo. Neurology, 55, 1904-1905. http://dx.doi.org/10.1212/WNL.55.12.1904

[15] Barry, J.J. and Sanborn, K. (2001) Etiology, Diagnosis and Treatment of Nonepileptic Seizures. Current Neurology and Neuroscience Reports, 1, 381-389. http://dx.doi.org/10.1007/s11910-001-0094-7

[16] Reuber, M. and Elger, C.D. (2003) Psychogenic Nonepileptic Seizures: Review and Update. Epilepsy \& Behavior, 4, 205-216. http://dx.doi.org/10.1016/S1525-5050(03)00104-5

[17] Reuber, M., Pukrop, R., Bauer, J., Helmstaedter, C., Tessendorf, N. and Elger, C.E. (2003) Outcome in Psychogenic Nonepileptic Seizures: 1 to 10-year Follow-Up in 164 Patients. Annals of Neurology, 53, 305-311. http://dx.doi.org/10.1002/ana.3000

[18] Martin, R.C., Gilliam, F.G., Kilgore, M., Faught, E., Kuzniecky, R. (1998) Improved Health Care Resource Utilization Following Video-EEG-Confirmed Diagnosis of Nonepileptic Psychogenic Seizures. Seizure, 7, 385-390. http://dx.doi.org/10.1016/S1059-1311(05)80007-X

[19] Brodie, M.J. and Kwan, P. (2002) Staged Approach to Epilepsy Management. Neurology, 58, S2-S8. http://dx.doi.org/10.1212/WNL.58.8_suppl_5.S2

[20] Kwan, P. and Brodie, M.J. (2001) Effectiveness of First Antiepileptic Drug. Epilepsia, 42, 1255-1260. http://dx.doi.org/10.1046/j.1528-1157.2001.04501.x

[21] Szaflarski, J.P., Szaflarski, M., Hughes, C., Ficker, D.M., Cahill, W.T. and Privitera, M.D. (2003) Psychopathology and Quality of Life: Psychogenic Non-Epileptic Seizures versus Epilepsy. Medical Science Monitor, 9, CR165-CR170.

[22] Benbadis, S.R. and Hauser, W.A. (2000) An Estimate of the Prevalence of Psychogenic Non-Epileptic Seizures. Seizure, 9, 280-281. http://dx.doi.org/10.1053/seiz.2000.0409

[23] Benbadis, S.R., Agrawal, V. and Tatum IV, W.O. (2001) How Many Patients with Psychogenic Nonepileptic Seizures Also Have Epilepsy? Neurology, 57, 915-917. http://dx.doi.org/10.1212/WNL.57.5.915

[24] Lesser, R.P. (1996) Psychogenic Seizures. Neurology, 46, 1499-1507. http://dx.doi.org/10.1212/WNL.46.6.1499

[25] Reuber, M., Fernandez, G., Helmstaedter, C., Qurishi, A. and Elger, C.E. (2002) Evidence of Brain Abnormality in Patients with Psychogenic Nonepileptic Seizures. Epilepsy \& Behavior, 3, 249-254. http://dx.doi.org/10.1016/S1525-5050(02)00004-5

[26] Lowe, M.R., De Toledo, J.C., Rabinstein, A.A. and Giulla, M.F. (2001) Correspondence on: MRI Evidence of Mesial Temporal Sclerosis in Patients with Psychogenic Nonepileptic Seizures. Neurology, 56, 820-823. http://dx.doi.org/10.1212/WNL.56.6.820-b

[27] Benbadis, S.R., Tatum IV, W.O., Murtagh, R. and Vale, F.L. (2000) MRI Evidence of Mesial Temporal Sclerosis in Patients with Psychogenic Nonepileptic Seizures. Neurology, 55, 1061-1062. http://dx.doi.org/10.1212/WNL.55.7.1061

[28] Martin, R., Burneo, J.G., Prasad, A., Powell, T., Faught, E., Knowlton, R., Mendez, M. and Kuzniecky, R. (2003) Frequency of Epilepsy in Patients with Psychogenic Seizures Monitored by Video-EEG. Neurology, 61, 1791-1792. http://dx.doi.org/10.1212/01.WNL.0000098890.13946.F5

[29] Alper, K.A., Devinsky, O., Perrine, K., Vazquez, B. and Luciano, D. (1993) Nonepileptic Seizures and Childhood Sexual and Physical Abuse. Neurology, 43, 1950-1953. http://dx.doi.org/10.1212/WNL.43.10.1950

[30] Krawetz, P., Fleisher, W., Pillay, N., Staley, D., Arnett, J. and Maher, J. (2001) Family Functioning in Subjects with Pseudoseizures and Epilepsy. The Journal of Nervous and Mental Disease, 189, 38-43. http://dx.doi.org/10.1097/00005053-200101000-00007

[31] Bowman, E.S. and Markand, O.N. (1996) Psychodynamics and Psychiatric Diagnoses of Pseudoseizure Subjects. American Journal of Psychiatry, 153, 57-63. 
[32] Reilly, J., Baker, G.A., Rhodes, J. and Salmon, P. (1999) The Association of Sexual and Physical Abuse with Somatization: Characteristics of Patients Presenting with Irritable Bowel Syndrome and Non-Epileptic Attack Disorder. Psychological Medicine, 29, 399-406. http://dx.doi.org/10.1017/S0033291798007892

[33] LaFrance Jr., W.C. and Devinsky, O. (2002)Treatment of Nonepileptic Seizures. Epilepsy \& Behavior, 3, S19-S23. http://dx.doi.org/10.1016/S1525-5069(02)00505-4

[34] Bowman, E.S. (2001) Psychopathology and Outcome in Pseudoseizures. In: Ettinger, A.B. and Kanner, A.M., Eds., Psychiatric Issues in Epilepsy: A Practical Guide to Diagnosis and Treatment, Lippincott, Williams \& Wilkins, Philadelphia, 355-377.

[35] Reuber, M., Pukrop, R., Bauer, J., Derfuss, R. and Elger, C.E. (2004) Multidimensional Assessment of Personality in Patients with Psychogenic Non-Epileptic Seizures. Journal of Neurology, Neurosurgery Psychiatry, 75, 743-748. http://dx.doi.org/10.1136/jnnp.2003.013821

[36] Ettinger, A.B., Devinsky, O., Weisbrot, D.M., Goyal, A. and Shashikumar, S. (1999) Headaches and Other Pain Symptoms among Patients with Psychogenic Non-Epileptic Seizures. Seizure, 8, 424-426. http://dx.doi.org/10.1053/seiz.1999.0334

[37] Griffith, J.L., Polles, A. and Griffith, M.E. (1998) Pseudoseizures, Families, and Unspeakable Dilemmas. Psychosomatics, 39, 144-153. http://dx.doi.org/10.1016/S0033-3182(98)71361-1

[38] Frances, P.L., Baker, G.A. and Appleton, P.L. (1999) Stress and Avoidance in Pseudoseizures: Testing the Assumptions. Epilepsy Research, 34, 241-249. http://dx.doi.org/10.1016/S0920-1211(98)00116-8

[39] Dikel, T.N., Fennell, E.B. and Gilmore, R.L. (2003) Posttraumatic Stress Disorder, Dissociation, and Sexual Abuse History in Epileptic and Nonepileptic Seizure Patients. Epilepsy \& Behavior, 4, 644-650. http://dx.doi.org/10.1016/j.yebeh.2003.08.006

[40] Bowman, E.S. (2000) Relationship of Remote and Recent Life Events to the Onset and Course of Non-Epileptic Seizures. In: Gates, J.R. and Rowan, A.J., Eds., Non-Epileptic Seizures, 2nd Edition. Butterworth-Heinemann, Boston, 269-283.

[41] Reuber, M. and House, A.O. (2002) Treating Patients with Non-Epileptic Seizures. Current Opinion in Neurology, 15, 207-211. http://dx.doi.org/10.1097/00019052-200204000-00014

[42] Bowman, E.S. (1999) Nonepileptic Seizures: Psychiatric Framework, Treatment, and Outcome. Neurology, 53, S84-S88.

[43] LaFrance Jr., W.C., Keitner, G.I., Papandonatos, G.D., Blum, A.S., Machan, J.T., Ryan, C.E. and Miller, I.W. (2010) Pilot Pharmacologic Randomized Controlled Trial for Psychogenic Non-Epileptic Seizures. Neurology, 75, 1166-1173. http://dx.doi.org/10.1212/WNL.0b013e3181f4d5a9

[44] Mayor, R., Smith, P.E. and Reuber, M. (2011) Management of Patients with Nonepileptic Attack Disorder in the United Kingdom: A Survey of Healthcare Professionals. Epilepsy Behavior, 21, 402-406. http://dx.doi.org/10.1016/j.yebeh.2011.05.019

[45] Aboukasm, M., Mahr, G., Gahry, B.R., Thomas, A. and Barkley, G.L. (1998) Retrospective Analysis of the Effects of Psychotherapeutic Interventions on Outcomes of Psychogenic Nonepileptic Seizures. Epilepsia, 39, 470-473. http://dx.doi.org/10.1111/j.1528-1157.1998.tb01407.x

[46] Alsaadi, T.M. and Vinter Marquez, A. (2005) Psychogenic Nonepileptic Seizures. American Family Physicians, 72, 849-856.

[47] Oto, M., Espie, C., Pelosi, A., Selkirk, M. and Duncan, R. (2005) The Safety of Antiepileptic Drug Withdrawal in Patients with Non-Epileptic Seizures. Journal of Neurology, Neurosurgery Psychiatry, 76, 1682-1685. http://dx.doi.org/10.1136/jnnp.2005.064063

\section{Abbreviations}

Nonepileptic Seizures: NES

Psychogenic Nonepileptic Seizures: PNES

Epileptic Seizures: ES

Video-EEG Monitoring: VEEG

Prolactin: PRL

Posttraumatic Stress Syndrome: PTSD 
Scientific Research Publishing (SCIRP) is one of the largest Open Access journal publishers. It is currently publishing more than 200 open access, online, peer-reviewed journals covering a wide range of academic disciplines. SCIRP serves the worldwide academic communities and contributes to the progress and application of science with its publication.

Other selected journals from SCIRP are listed as below. Submit your manuscript to us via either submit@scirp.org or Online Submission Portal.
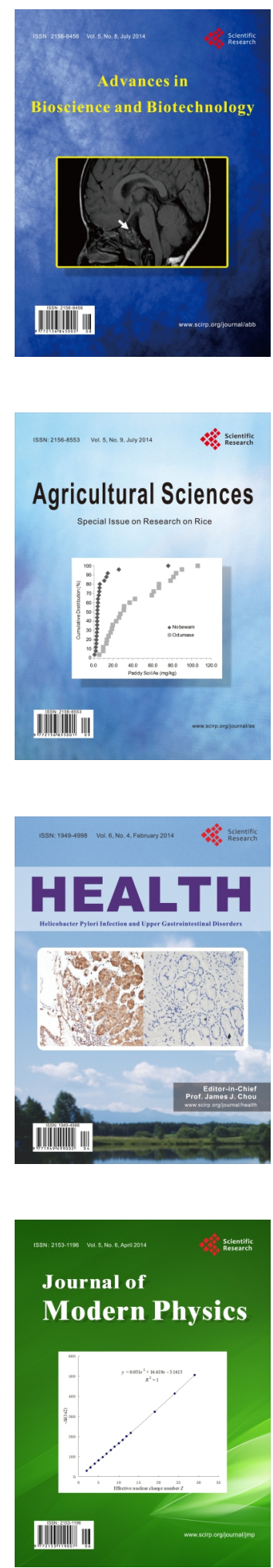
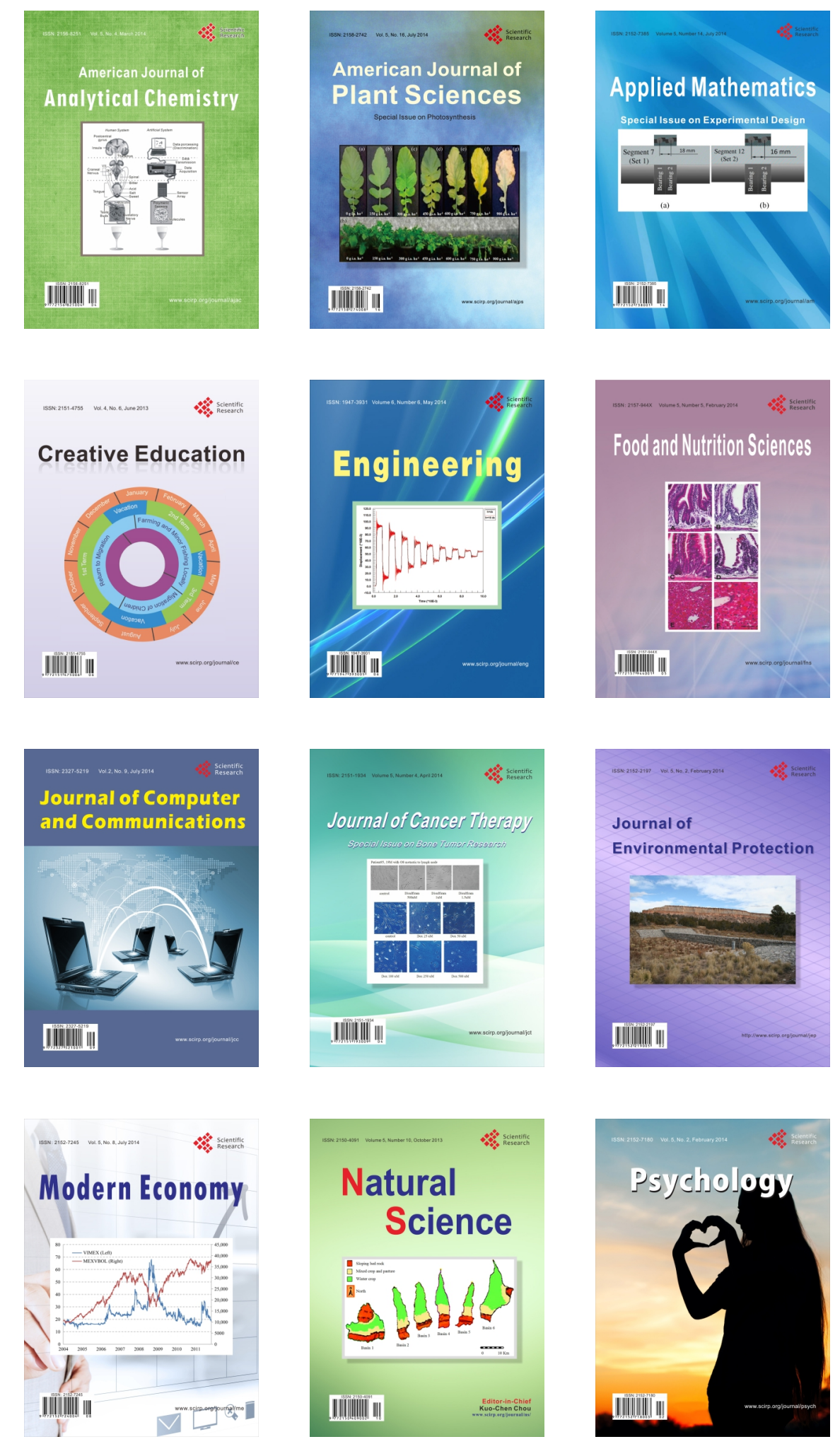